\title{
Urban Households' Resilience to Climate Change in Nigeria: Evidence from Yenagoa Metropolis
}

\author{
Odafivwotu Ohwo*, Eseoghene Frank Evwienure \\ Email address: \\ drohwodafe@gmail.com (O. Ohwo), frankeseoghene@gmail.com (E. F. Evwienure) \\ *Corresponding author
}

Department of Geography and Environmental Management, Niger Delta University, Wilberforce Island, Nigeria

\section{To cite this article:}

Odafivwotu Ohwo, Eseoghene Frank Evwienure. Urban Households' Resilience to Climate Change in Nigeria: Evidence from Yenagoa Metropolis. International Journal of Natural Resource Ecology and Management. Vol. 6, No. 2, 2021, pp. 56-64.

doi: $10.11648 /$ j.ijnrem.20210602.15

Received: April 21, 2021; Accepted: May 18, 2021; Published: May 27, 2021

\begin{abstract}
Increasing urban households' capacities to withstand climate change will in many ways reduce the shocks connected with it. This study focused on urban households' capabilities to withstand climate change in Nigeria, based on evidence from Yenagoa metropolis. The study adopted survey design, which involved direct physical observation of households' environment and the distribution of a set of 400 structured questionnaires to systematically sampled households. Responses to the administered questionnaire constituted the data, which contains 19 households' resilience indicators. The data was analyzed with a household climate resilience index (HCRI) and descriptive statistics. The findings revealed that households' in Yenagoa have low coping abilities to change in climate, since HCRI value was 2.35 points on a 5 point scale. The twelfth resilience indicator, impact of government in the neighbourhood had the least rating, with a calculated resilience weight index of 1.47 points; while the nineteenth indicator, access to good communication facilities had the highest rating of 3.25 points on a 5 point scale. It was therefore recommended that government should provide more infrastructural amenities and design livelihood improvement programmes for urban households, to boost their capabilities to withstand change in climate.
\end{abstract}

Keywords: Climate Change, Households, Nigeria, Resilience, Urban

\section{Introduction}

Today, cities and their entire systems are susceptible to the effects of climate change and calamities that may occur naturally or man-made. For instance, the recent episodes of flood disasters experienced world-wide, especially in Nigeria (2012, 2018 and 2019) is clear evidence that coastal cities and low lying areas are not prepared to face the shocks of climate related events. However, cities should continuously maintain their functions and provide succor to the citizens and facilities. Therefore, increasing urban capabilities to withstand climate-related multiple stresses and other events will prove crucial for Nigerian cities abilities to sustainably carryout their functions and ensure improved living for residents.

To improve the livability index of cities, the UN devoted SDG11 to achieve resilience and sustainability of cities. This sustainability goal cannot be achieved without explicitly recognizing climate change as fundamental component [1], since it has exerted significant negative impacts (flooding, increase temperature, salt water intrusion, habitat destruction etc) on human, socioeconomic, ecological and geophysical systems. More still, the anticipated future effects of climate change could be severe and devastating if urgent steps are not taken to moderate the projected impacts. Hence many United Nations (UN) agencies, governmental and non-governmental organizations, researchers and urban planners believe that enhancing the abilities of cites to moderate the anticipated climate change stresses will help in strengthening the various subsystems in a city. This reasoning has made 'resilience' to gain much prominence over the years.

Although resilience is fundamental in the contemporary debate on climate change and adaptation [2], however, resilience is applied very differently by various institutions, disciplines and researchers. Resilience is the capability of any system to overcome distress and still maintains its 
identity and sustains the capacity for adaptation, learning and transformation [3]. It is also known as a city's capability to reduce exposure to, and learn from climatic variability [4]. The city's strength derives from its capacity to reduce risk and response capabilities, which include retaining or improving physical, social, institutional, environmental and governance structures within a city. Specifically, 'resilience city' is a city which has the strength to withstand stresses, including the capability to plan/prepare, absorb and resist such disturbances [5]. For a city to be resilience it must have network of human communities and physical systems that are sustainable, without which it would be susceptible to climaterelated disasters [2].

Despite the divergent views on resilience, the literature reveals that it is mainly seen as the capability of anysystem to overcome major shocks and maintain its normal function [5]. However, among practitioners, there is no general defining characteristics and analytical unit for its measurement. Hence, different conceptual frameworks are used at different scales to determine resilience. Different approaches, which include urban ecological resilience; urban disaster risk and hazards reduction; resilience of city and regional economies; and urban governance and institutions, have been identified [5]. Although there exist overlap in the approaches in the literature, however, each focused on different aspects and components of cites and urban systems [5].

This situation resulted in multiple methods and scales of measurements. The multiple methods adopted in the literature include qualitative, quantitative, objective, subjective, indirect and direct methods; while the multiple scales of measurement include household, community, region, national and systems scales. For this reason, several indexes have been used as proxy to gauge urban resilience at different scales of measurements in the literature. Examples include, a "climate resilience index" (CRI) model [6]; subjective approach to resilience measurement [7]; while the US EPA developed a framework, which combined both quantitative and qualitative information to assess resilience. The framework not only includes exposure, vulnerability and hazards that present risks to urban environments, but it also incorporates feedbacks, learning over time, and evolving in the ability to withstand challenges presented by extreme and gradual climate change [4]. The framework serves as a means of determining the type and breadth of indicators needed to appraise a city's resilience condition and evolution over time.

Since no generally acceptable index is used in the literature for measuring households' resilience to climate change (HRCC), this study joins the debate and search for appropriate indicators tocombine with other sets of indicators in the literature to offer a better measure of HRCC. This study therefore provides a HCRI model, which contains 19 indicators that measured the resilience status of households to climate change stresses and shocks. The index is based on the assessment of individual household's capability to adjust to climate-induced stresses and shocks. The model could assess an individual household's resilience or that of a community or urban area by integrating the responses by various respondents in the chosen unit of analysis. Since the calculated index was derived from household's self assessment, they would be concerned about their current resilience status and be more willing to take measures to boast their resilience level. Such measures will increase the community or urban area overall resilience to climate change.

A fundamental step in planning for resilience should be the determination of urban households' preparedness to face the challenges related to climate change and other associated shocks that the city may experience from time to time. This knowledge would guide policy makers to design the most appropriate methods that would enhance the city resilience by tackling the drivers that weakens its capabilities. Since Yenagoa is located on lowland and highly vulnerable to flooding, which has resulted to huge loss of lives and property, this study analyzed the preparedness of households' to change in climate in Yenagoa. The HCRI model was employed to examine HRCC in Yenagoa. This would enable policy makers to develop adequate strategies to strengthen HRCC.

\section{The Study Area}

Yenagoa is the capital of Bayelsa State; located within latitudes $4^{\circ} 55^{\prime}$ and $5^{\circ} 02^{\prime}$ North and longitudes $6^{\circ} 15^{\prime}$ and $6^{\circ}$ 25' East (Figure 1). It lies on a plain, less than $15 \mathrm{~m}$ [8]. Yenagoa is drained by two major creeks-Ekole and Epie, and has an Equatorial type of climate (Koppen's Af classification) which is characterized by two dominant seasons, which occurs from April-October (rainy) and from NovemberMarch (dry), respectively. However, there is hardly a month without a record of rainfall. The annual rainfall is about 3000 $\mathrm{mm}$, relative humidity of over 70 per cent and a daily temperature of about $28^{\circ} \mathrm{C}$.

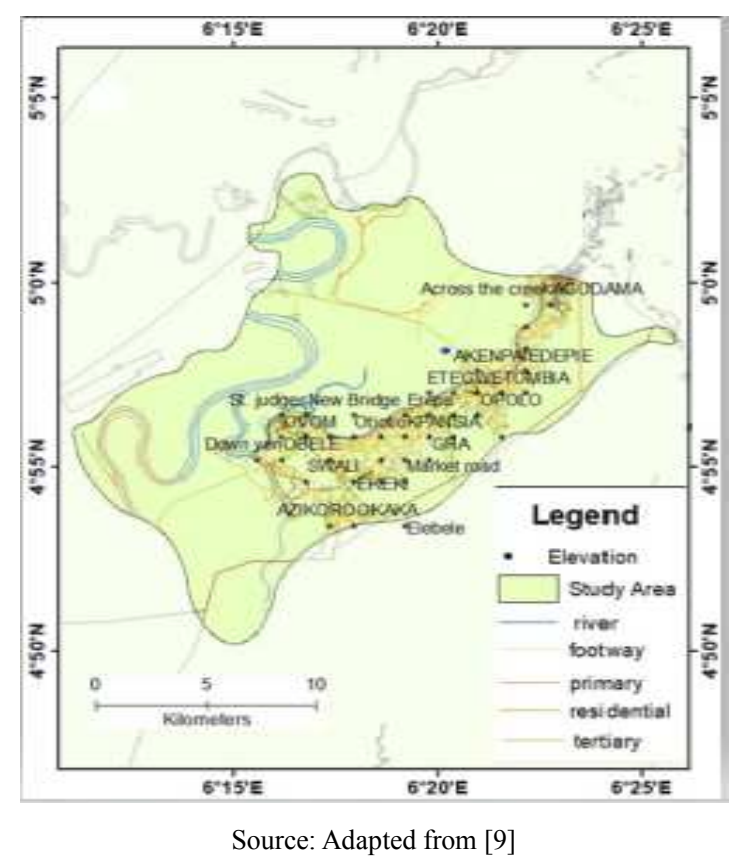

Figure 1. Map of Yenagoa Metropolis. 
Since Yenagoa became a state capital, it has witness high influx of migrants from the neighbouring villages and towns due to the perceived opportunities offered by the city. Unfortunately, infrastructural amenities in Yenagoa lag behind urban growth. This has created pressure on existing amenities and development of slums in the city, where some houses are built on flood plains and natural drainage channels due to poor urban control and management. All these conditions have exacerbated the urban challenges and increased the susceptibility of Yenagoa to climate-related stresses. To increase the livability index of Yenagoa, its resilience to climate-related and other stresses has to be strengthened.

\section{Method of Study}

This paper analyzed urban households' resilience to climate change in Nigeria using evidence from Yenagoa. To achieve this, the study adopted the survey design, using questionnaire and direct physical observation of households' living environment and conditions. Data required are primary, which were gotten from responses to the administered set of questionnaire. The population of the study was the entire households $(75,000)$ in Yenagoa, which was estimated using four persons per household [10]. The sample size was derived with the equation $\left[S=X^{2} N P(1-P)\right.$ $\left.\div d^{2}(N-1)+X^{2} P(1-P)\right]$ for estimating sample size from a given population; where $S$, required sample size; $X^{2}$, table value of chi-square at d.f. $=1$ for desired confidence level; $\mathrm{N}$, the population size; $\mathrm{P}$, population proportion, 0.50 , and $\mathrm{d}$, degree of accuracy (0.05) [11]. From the calculation, 400 households constituted the sample size, which was selected using the classified and systematic sampling techniques. Firstly, the communities (20) in Yenagoa were structured into four zones; thereafter, 100 households were selected from each zone, which comprised of 400 households. In each zone, equal number (100) of questionnaire was directly administered by hand to household heads (male or female) that was available when the household was visited due to the unknown population figures of the respective zones.

The questionnaire was retrieved immediately after filling to prevent its loss. This was done by three assistants who were duly instructed and supervised by the authors. The questionnaire consists of two sections-demographic characteristics of respondents, and household's resilience drivers (indicators) to climate change. The selected 19 household resilience indicators were gotten from the literature. Responses to these resilience indicators were used to examine the level of households' resilience to climate change (HRCC) in Yenagoa.

The obtained data were analyzed with the aid of tables, percentages, and a HCRI model, used to assess HRCC based on respondents' responses to the 19 resilience indicators. Resilience weight of 1-5 was assigned to the indicators, which were classified in a likert scale of very high (5), high (4), medium (3), low (2) and very low (1), which means household's resilience increases as the calculated value increases. The model determines a household or group of HRCC by integrating the various responses to the 19 climate resilience indicators. The HCRI additive model is as follows:

$$
\begin{gathered}
\text { HCRI }=\sum_{i=1}^{n} \frac{\mathrm{Ri}}{\mathrm{N}}, \mathrm{i}=1,2,3 \ldots \ldots 19 \\
\text { Where Ri }=\sum_{i=1}^{n} \frac{\mathrm{nj}(\mathrm{wj})}{\mathrm{ti}}, \mathrm{j}=1,2,3,4,5
\end{gathered}
$$

HCRI = household climate resilience index; $\mathrm{Ri}=$ resilience weight index of unit indicator, a number between 1-19; wj = resilience unit weight, a number between $1-5 ; \mathrm{nj}=$ number of respondents to $\mathrm{jth}$ weight; $\mathrm{ti}=$ total respondents to ith indicator; $\mathrm{N}=$ number of indicators; $\Sigma=$ summation. The range of the HCRI is $1-5$ points, where the lowest value (1) means very low resilience, while the highest value (5) means very high resilience. The interpretation scale of the index is as follows: very high resilience $=4.0-5.0$; high resilience $=$ $3.0-3.99$; medium resilience $=2.50-2.99$; low resilience $=$ $1.50-2.49$ and very low resilience $=1.0-1.49$.

\section{Results and Discussion}

\subsection{Demographic Characteristics of Respondents}

Of the 400 questionnaire administered, 387 (96.75\%) copies were retrieved. Table 1 shows that male respondents were 239 (61.76\%), while the female respondents were 148 (38.24\%), which indicates that the views of both gender were represented. A similar sex distribution pattern of $60 \%$ (male) and $40 \%$ (female) was also recorded in another study in Yenagoa [12]. The age structure revealed that $65.11 \%$ were in the age range of $25-65$ years; while $34.89 \%$ respondents were within the dependent population range of 1-25 years and above 65 years. The marital status shows that $278(71.83 \%)$ respondents were married, 101 (26.10\%) respondents were single; while $4(1.03 \%)$ respondents each were divorced and widowed, respectively. The household size of 4-6, had the highest respondents (140), which represents $36.18 \%$; while households with 10 and above persons had the lowest response of 54 (13.95\%).

The educational status of respondents shown in Table 1 revealed that secondary school holders had the highest responses of $151(39.02 \%)$, while those with postgraduate education had the lowest responses of $21(5.43 \%)$. However, $30(7.75 \%)$ respondents had no formal education. Since $69.51 \%$ of the respondents had secondary education and above, it implies that the issue of climate change may not be entirely new to them. The occupational distribution reveals that the highest number of respondents (102), were self employed, which represents $26.36 \%$; while students had the lowest responses (25), representing 6.46\%. Only 95 (24.55\%) respondents were in the civil service (government employment); while $60.47 \%$ were either self employed, in the private sector or in business. This indicates that the views of respondents in major sectors of the economy were duly represented. The monthly income distribution shows that majority (175) respondents $(45.22 \%)$ earned between N100,000-N149,000 (\$278-\$413); while only 4 (1.03\%) respondents earned above N250,000 (\$694) monthly. The income distribution shows that $90.44 \%$ of the households 
were medium to low income earners. Similar distribution was reported in another study in Yenagoa, where 94.64\% were medium to low income earners [10]. This income level might weaken HRCC shocks when they occur, as it may be more challenging for such households to raise money to bounce back and recover after experiencing a disaster.

Table 1. Demographic Characteristics of Respondents.

\begin{tabular}{|c|c|c|c|c|}
\hline $\mathbf{S} / \mathbf{N}$ & Questionnaire Variable & Response Variable & Number of Respondents & Percentage Response (\%) \\
\hline \multirow{2}{*}{1} & \multirow{2}{*}{ Sex } & Male & 239 & 61.76 \\
\hline & & Female & 148 & 38.24 \\
\hline \multirow{4}{*}{2} & \multirow{4}{*}{ Age } & Below 25 years & 110 & 28.42 \\
\hline & & $25-40$ years & 154 & 39.79 \\
\hline & & $41-65$ years & 98 & 25.32 \\
\hline & & Above 65 years & 25 & 6.46 \\
\hline \multirow{4}{*}{3} & \multirow{4}{*}{ Marital status } & Married & 278 & 71.83 \\
\hline & & Single & 101 & 26.10 \\
\hline & & Divorced & 4 & 1.03 \\
\hline & & Widow/widower & 4 & 1.03 \\
\hline \multirow{4}{*}{4} & \multirow{4}{*}{ Household size } & $1-3$ & 102 & 26.36 \\
\hline & & $4-6$ & 140 & 36.18 \\
\hline & & $7-9$ & 91 & 23.51 \\
\hline & & 10 and above & 54 & 13.95 \\
\hline \multirow{5}{*}{5} & \multirow{5}{*}{ Education status } & Postgraduate & 21 & 5.43 \\
\hline & & First degree & 97 & 25.06 \\
\hline & & Secondary & 151 & 39.02 \\
\hline & & Primary & 88 & 22.74 \\
\hline & & No formal education & 30 & 7.75 \\
\hline \multirow{6}{*}{6} & \multirow{6}{*}{ Occupation } & Student & 25 & 6.46 \\
\hline & & Civil servant & 95 & 24.55 \\
\hline & & Self employed & 102 & 26.36 \\
\hline & & Private sector & 33 & 8.53 \\
\hline & & Business & 99 & 25.58 \\
\hline & & Others & 33 & 8.53 \\
\hline \multirow{5}{*}{7} & \multirow{5}{*}{ Monthly income status } & Above N250,000 & 4 & 1.03 \\
\hline & & $\mathrm{N} 150,000-\mathrm{N} 249,000$ & 33 & 8.53 \\
\hline & & $\mathrm{N} 100,000-\mathrm{N} 149,000$ & 175 & 45.22 \\
\hline & & $\mathrm{N} 50,000-\mathrm{N} 99,000$ & 125 & 32.30 \\
\hline & & Below N50,000 & 50 & 12.92 \\
\hline
\end{tabular}

Source: Author's fieldwork, 2019

\subsection{Households Resilience to Climate Change}

The HRCC was determined using the responses to the 19 selected resilience indicators as shown in Table 2. These indicators were drawn from the physical environment, socioeconomic factors and infrastructural provisions. The first resilience indicator, protection against flooding in the neighbourhoods showed that $70(18.09 \%), 72(18.60 \%)$ and $141(36.43 \%)$ households have medium, low to very low protection against flooding, respectively. This is an indication that $73.13 \%$ of the households were vulnerable to flooding as against only $26.87 \%$ who were either highly or very highly protected against flooding. This response reflected the facthat over $60 \%$ of Yenagoa was covered by flood waters during the 2012 and 2017 flood episodes. This situation is a confirmation that due to sea level rise, coastal, and areas of low elevation would increasingly experience inundation, flooding and erosion [13]. The location of Yenagoa in the Niger Delta, its height above sea level, high precipitation pattern and poor urban planning, control and management have increased the exposure of the people to flood hazards, which have reduced their capacities to withstand climate change shocks and stresses. Despite the high susceptibility of Yenagoa to flooding, most neghbourhoods have inadequate drainage systems, which could help to moderate flood waters and facilitate the rate of flood water recession. Responses to the second indicator, drainage in neighbourhoods revealed that $74.16 \%$ of the respondents indicated either low (16.02\%) or very low (58.14\%); while $16.27 \%$ indicated medium and only $9.56 \%$ indicated either high or very high. The direct physical observation made in the field confirms the response pattern. Also, an earlier study on residents' perception on urban aesthetics in Yenagoa reported that $81.63 \%$ of the respondents perceived the drainage network to be either inadequate or very inadequate [10].

Floods come with different forms of losses, which may include life, properties and the disruption of socioeconomic activities. However, responses to the third indicator, protection against losses due to flooding and other climate induced hazards was not encouraging as $16.02 \%$ respondents indicated medium, $25.58 \%$ others low, while another group of $19.12 \%$ indicated very low. This shows that many households are susceptible to losses due to climate-induced hazards. Similarly, increase in climate-related risks had led to loss of income and livelihoods and further increased the cost of healthcare and property maintenance [14]. Added to this situation is the fact that the rate of recovery from flooding and other natural hazards (fourth indicator) was poor, as only 
$16.28 \%$ households indicated either high or very high rate of recovery. The poor rate of households' recovery from a disaster may exacerbate the suffering of the household and further expose them to other urban shocks and stresses.

Households recovery rate from flood episodes may be influenced by the severity of the hazard, amount of losses incurred and the financial disposition of the household. Also, the quality of the environment where the household is located could influence the resilience of the household to the impact of climate change. Poor environmental quality promotes the spread of diseases and illness, which could lead to death. When flooding occurs in such an area it exacerbates the already bad condition thereby weakening the abilities of affected households to adapt and fully recover from the associated impacts.

Unfortunately, only $9.56 \%$ of households indicated either high or very high environmental quality; while $60.21 \%$ households either indicated low or very low environmental quality (fifth indicator). This response pattern was confirmed by direct physical observations during the fieldwork and a previous study in Yenagoa [15].

Adequate housing quality is one of the basic needs of man after air, water and food. Good quality houses provide shelter for households, protection against communicable diseases; reduce psychological and social stresses to a minimum. Hence, it is not enough to provide structurally stable structures as houses, but they must be so located and designed in such a way that they provide convenience, amenity, health and social life to individuals, households and the community [16]. In effect, quality housing can increase HRCC impacts. However, the housing stock in Yenagoa fell short of adequate quality. For example, $82.02 \%$ households rated their housing quality as either moderate $(42.9 \%)$, low $(32.30 \%)$ or very low $(9.82 \%)$; while only $14.99 \%$ households indicated high or very high quality (sixth indicator). This finding agrees with what was reported in a study of housing quality in Yenagoa [8]. The study used a housing quality index (HQI) model that comprises of 16 quality parameters and concluded that the housing quality in Yenagoa was inadequate. Another study equally concluded that the housing facilities in Yenagoa were inadequate [15]. Houses built with poor materials can easily collapse and eroded away by high floods, thereby weakening the resilience of affected households to severe shocks and stresses.

HRCC and other urban shocks can be enhanced with adequate provision and access of households' to basic infrastructural facilities such as water, healthcare, sanitation and hygiene, electricity and waste management. However, these facilities are poorly provided in Yenagoa metropolis. For example, access to electricity was very unsatisfactory as $87.60 \%$ households' either indicated low or very low access; while $7.75 \%, 2.33 \%$ and another $2.33 \%$ indicated medium, high and very high access, respectively (seventh indicator). Electricity is the engine room that drives any modern economy, and the lack of it only portends slow socioeconomic growth and low livability index of households in the metropolis. This in effect will impact negatively on households' adaptation and recovery from shocks and stresses associated with climate change. Responses to the eighth indicator, access to healthcare facilities was also poor, as $64.60 \%$ of households' have low to very low access; while only $6.46 \%$ households have high to very high access. This situation would make emergency health response to disease outbreaks arising from flooding and other hazards difficult to control and managed effectively.

Responses to the ninth indicator show that 58.65\% households have low to very low access to potable water supply, as many of the households used well and boreholes for their daily water needs despite the poor water quality obtainable from these sources [8]. The consumption of water from these poor quality sources without treatment could increase the likelihood of contracting waterborne diseases. Since most of the households obtain their water supply from groundwater, during floods these water sources are inundated causing serious challenges for households to meet their daily water needs. Since water is needed by households to practice adequate sanitation and hygiene, probably explain why $59.69 \%$ of respondents indicated low or very low access to sanitation and hygiene (tenth indicator), which are veritable medium for the transmission of different types of diseases. Closely related to sanitation and hygiene is waste disposal, which was equally poorly rated as $60.21 \%$ of households have either low or very low access to waste management (eleventh indicator). This was evident during the fieldwork as waste was seen disposed indiscriminately in some locations in the metropolis. This could constitute threat to public health and provide breeding grounds for flies, mosquitoes and rodents, which are notable for spreading diseases of different kinds. Since government is saddled with the responsibilities for the provision of infrastructural facilities in the metropolis explains why an overwhelming $90.44 \%$ of households indicated that the impact of government was not felt in their neighbourhoods (twelfth indicator).

The income status of households is a major determinant of the level of resilience they have against climate change impacts. In preparing for or recovering from any hazard, money is required to meet various needs. Hence, the rich tend to suffer less and recover faster from any hazard when compared to their poor counterparts. One of the reasons why the poor suffers more losses is that they live in places which are very vulnerable to different forms of hazards due to lack of resources to live in better protected areas. Responses to income status revealed that $90.44 \%$ households earned medium (N100,000-N149,000 or \$278-\$414), low (N50,000$\mathrm{N} 99,000$ or $\$ 139-\$ 275)$ and very low (below $\mathrm{N} 50,000$ or $\$ 139$ ) monthly incomes, respectively; while only $9.56 \%$ households earned either high (N150,000-N249,000 or \$417$\$ 692$ ) or very high (above $\mathrm{N} 250,000$ or $\$ 694$ ) monthly income (thirteenth indicator). This response pattern shows that most households may find it very challenging to recover from any major climate induced hazards such as flooding when they occur. Since access to credit facilities is largely dependent on income status, therefore, it's not surprising that $65.63 \%$ households have low or very low access to credit; 
while $20.41 \%, 9.56 \%$ and $4.39 \%$ households have medium, high and very high access to credit facilities, respectively (fourteenth indicator). A study in Malaysia also reported similar situation where the two cities studied lacked credit facility and disaster risk financing, which indicated that credit facilities need to be improved to allow local communities within disaster prone areas to have options in the preparation to face any future disaster [17].

Apart from personal income and access to credit, households with dependable family support system tend to recovery faster from shocks and stresses than those with poor or no family support system as both sociological and psychological impacts of hazards on households are easily ameliorated by a strong family support system. Responses to the fifteenth indicator, family support system, shows that $35.40 \%, 24.81 \%$ and $21.45 \%$ respondents, respectively indicated they have medium, low and very low family support system; while only $11.89 \%$ and $6.46 \%$ indicated high and very high family support system, respectively. In addition, households that enjoy food security are better prepared to withstand and recover from climate change induced-hazards. Food is needed for human survival; therefore, food security makes it easier for households to keep sustenance, maintain good health and deal with other challenges. However, responses to food security revealed that only $10.59 \%$ households had high or very high food security; while $89.40 \%$ households either indicated medium, low or very low food security (sixteenth indicator). The response pattern was closely related to the income distribution of households in the metropolis. Hence, a study noted that in
Shewa, Ethiopia, inadequate access to cash during crisis limits the resilience of households to climate change-induced shocks [18].

Education is power, and those educated are usually abreast with developments in their immediate environment. Having prior information about an impending disaster enables one to prepare adequately, which helps to ameliorate or avoid the associated impacts of the disaster. It is therefore expected that those with reasonable knowledge of climate change may be more prepared to develop coping/adaptation strategies to withstand the impact of climate change. Although about $92 \%$ of the respondents have at least primary education, $30.49 \%$ respondents describe their knowledge of climate change as either low or very low (seventeenth indicator). This implies that such persons may be unprepared for any immediate climate change-related disaster. It should be noted however, that having knowledge of climate change is not a guaranty to be adequately prepared for climate change shocks and stresses, but access to quality climate change information/early warning system usually prove to be more valuable in preparing for a disaster. Responses to the eighteenth indicator, access to quality climate change information/early warning systems show that $51.16 \%$ respondents had low to very low access to climate change information and early warning on impending climate change related disasters. A similar study in Kajang and Ampang in Malaysia, equally reported that the cities lacked early warning systems and the implementation of disaster drills [17]. In effect, households in these cities may be highly vulnerable to climate change shocks and stresses.

Table 2. Households Response to Resilience Indicators to Climate Change.

\begin{tabular}{|c|c|c|c|c|c|c|}
\hline \multirow{2}{*}{$\mathbf{S} / \mathbf{N}$} & \multirow{2}{*}{ Resilience Indicators } & Very high & High & Medium & Low & Very low \\
\hline & & Response (\%) & Response (\%) & Response (\%) & Response (\%) & Response (\%) \\
\hline 1 & Protection against flooding in your neighbourhold & $62(16.02)$ & $42(10.85)$ & $70(18.09)$ & $72(18.60)$ & $141(36.43)$ \\
\hline 2 & Drainage in your neighbourhood & $8(2.07)$ & $29(7.49)$ & $63(16.27)$ & $62(16.02)$ & $225(58.14)$ \\
\hline 3 & $\begin{array}{l}\text { Protection against losses due to flooding and other } \\
\text { climate induced hazards }\end{array}$ & $103(26.61)$ & $49(12.66)$ & $62(16.02)$ & $99(25.58)$ & $74(19.12)$ \\
\hline 4 & $\begin{array}{l}\text { Rate of recovery from flooding and other natural } \\
\text { hazards }\end{array}$ & $34(8.79)$ & $29(7.49)$ & $84(21.71)$ & $118(30.49)$ & $122(31.52)$ \\
\hline 5 & Environmental quality & $8(2.07)$ & $29(7.49)$ & $117(30.23)$ & $121(31.27)$ & $112(28.94)$ \\
\hline 6 & Housing quality & $25(6.46)$ & $33(8.53)$ & $166(42.9)$ & $125(32.30)$ & $38(9.82)$ \\
\hline 7 & Access to electricity & $9(2.33)$ & $9(2.33)$ & $30(7.75)$ & $146(37.73)$ & $193(49.87)$ \\
\hline 8 & Access to healthcare facilities & $8(2.07)$ & $17(4.39)$ & $112(28.94)$ & $129(33.33)$ & $121(31.27)$ \\
\hline 9 & Water access and quality & $16(4.13)$ & $45(11.63)$ & $99(25.58)$ & $111(28.68)$ & $116(29.97)$ \\
\hline 10 & Access to sanitation and hygiene & $16(4.13)$ & $25(6.46)$ & $115(29.72)$ & $124(32.04)$ & $107(27.65)$ \\
\hline 11 & Waste management & $4(1.03)$ & $29(7.49)$ & $121(31.27)$ & $133(34.37)$ & $100(25.84)$ \\
\hline 12 & Impact of government in the neighbourhood & $0(0.00)$ & $0(0.00)$ & $37(9.56)$ & $104(26.87)$ & $246(63.57)$ \\
\hline 13 & Income level & $4(1.03)$ & $33(8.53)$ & $175(45.22)$ & $125(32.30)$ & $50(12.92)$ \\
\hline 14 & Access to credit facilities & $17(4.39)$ & $37(9.56)$ & $79(20.41)$ & $100(25.84)$ & $154(39.79)$ \\
\hline
\end{tabular}

Table 2. Continued.

\begin{tabular}{|c|c|c|c|c|c|c|}
\hline \multirow{2}{*}{$\mathbf{S} / \mathbf{N}$} & \multirow{2}{*}{ Resilience Indicators } & Very high & High & Medium & Low & Very low \\
\hline & & Response (\%) & Response (\%) & Response (\%) & Response (\%) & Response (\%) \\
\hline 15 & Family support system & $25(6.46)$ & $46(11.89)$ & $137(35.40)$ & $96(24.81)$ & $83(21.45)$ \\
\hline 16 & Food security & $12(3.10)$ & $29(7.49)$ & $154(39.79)$ & $125(32.30)$ & $67(17.31)$ \\
\hline 17 & Knowledge of climate change & $21(5.43)$ & $97(25.06)$ & $151(39.02)$ & $88(22.74)$ & $30(7.75)$ \\
\hline 18 & $\begin{array}{l}\text { Access to climate change information/early warning } \\
\text { system }\end{array}$ & $25(6.46)$ & $59(15.25)$ & $105(27.13)$ & $122(31.52)$ & $76(19.64)$ \\
\hline 19 & Access to good communication facilities & $68(17.57)$ & $85(21.96)$ & $140(36.18)$ & $60(15.50)$ & $34(8.79)$ \\
\hline
\end{tabular}

Source: Author's fieldwork, 2019 
However, access to good communication facilities could enable one to reach out for help and obtain emergency information, which could speed up response time and ameliorate the impact of a disaster. Response to the nineteenth indicator shows that $75.71 \%$ respondents had medium, high and very high access to good communication facilities in the metropolis. This will enhance the speed of information dissemination on impending climate change related disasters, or call for help in the case of a disaster, which could help to reduce anticipated impacts.

\subsection{Indicator Rating and Calculated HRCC}

In order to determine the overall ratings of HRCC in Yenagoa, data in Table 2, which show households response to the 19 resilience indicators and the HCRI model defined in the method of study were used. The HCRI integrates the responses to each of the 19 resilience indicators by all respondents and produced a single value within the range of 1-5 points to determine the average level of resilience the households have against climate change in Yenagoa. Using the HCRI equation the resilience weight index of each unit indicator was calculated as presented in Table 3. The table revealed that the twelfth indicator, impact of government in the neighbourhood was the least rated resilience indicator with a calculated resilience weight index of 1.47 ; while the nineteenth indicator, access to good communication facilities was the highest rated indicator with a resilience weight index of 3.25 on a 5 point scale.

Table 3. Indicator Rating and Calculated HRC.

\begin{tabular}{|c|c|c|c|c|c|c|c|}
\hline $\mathbf{S} / \mathbf{N}$ & Resilience Indicators & $\begin{array}{l}\text { Very high } \\
\text { unit weight } \\
\text { (5) }\end{array}$ & $\begin{array}{l}\text { High unit } \\
\text { weight } \\
\text { (4) }\end{array}$ & $\begin{array}{l}\text { Medium } \\
\text { unit weight } \\
\text { (3) }\end{array}$ & $\begin{array}{l}\text { Low unit } \\
\text { weight ( } 2)\end{array}$ & $\begin{array}{l}\text { Very low unit } \\
\text { weight (1) }\end{array}$ & $\begin{array}{l}\text { Resilience weight } \\
\text { index of unit } \\
\text { indicator }(\mathrm{Ri})\end{array}$ \\
\hline 1 & $\begin{array}{l}\text { Protection against flooding in your } \\
\text { neighbourhold }\end{array}$ & 0.80 & 0.43 & 0.54 & 0.37 & 0.36 & 2.50 \\
\hline 2 & Drainage in your neighbourhood & 0.10 & 0.30 & 0.49 & 0.32 & 0.58 & 1.79 \\
\hline 3 & $\begin{array}{l}\text { Protection against losses due to flooding and } \\
\text { other climate induced hazards }\end{array}$ & 1.33 & 0.51 & 0.48 & 0.51 & 0.19 & 3.02 \\
\hline 5 & Environmental quality & 0.10 & 0.30 & 0.91 & 0.63 & 0.29 & 2.23 \\
\hline 6 & Housing quality & 0.32 & 0.34 & 1.29 & 0.65 & 0.10 & 2.70 \\
\hline 7 & Access to electricity & 0.12 & 0.09 & 0.23 & 0.76 & 0.50 & 1.70 \\
\hline 8 & Access to healthcare facilities & 0.10 & 0.18 & 0.87 & 0.67 & 0.31 & 2.13 \\
\hline 9 & Water access and quality & 0.21 & 0.47 & 0.77 & 0.57 & 0.30 & 2.32 \\
\hline 10 & Access to sanitation and hygiene & 0.21 & 0.26 & 0.89 & 0.64 & 0.28 & 2.28 \\
\hline 13 & Income level & 0.05 & 0.34 & 1.36 & 0.65 & 0.13 & 2.53 \\
\hline 14 & Access to credit facilities & 0.22 & 0.38 & 0.61 & 0.52 & 0.40 & 2.13 \\
\hline 15 & Family support system & 0.32 & 0.48 & 1.06 & 0.50 & 0.21 & 2.57 \\
\hline 16 & Food security & 0.16 & 0.30 & 1.19 & 0.65 & 0.17 & 2.47 \\
\hline 17 & Knowledge of climate change & 0.27 & 1.00 & 1.17 & 0.45 & 0.08 & 2.97 \\
\hline 18 & $\begin{array}{l}\text { Access to climate change information/early } \\
\text { warning system }\end{array}$ & 0.32 & 0.61 & 0.18 & 0.63 & 0.20 & 1.94 \\
\hline 19 & Access to good communication facilities & 0.88 & 0.88 & 1.09 & 0.31 & 0.09 & 3.25 \\
\hline
\end{tabular}

Source: Author's fieldwork, 2019

Table 3 also revealed that only seven indicators $(1,3,6$, $13,15,17, \& 19)$ had calculated resilience weight index of 2.50 points and above. In order words, twelve indicators exact significant drag on the calculated HCRI value of 2.35 points on a 5 point scale for the city. With reference to the HCRI interpretation scale as defined in the methods of study, a calculated value of 2.35 points means that an average household in Yenagoa had low resilience (1.50-2.49 points) to the impacts of climate change. Similar conclusions were reached in a study of 50 Spanish cities, where $60 \%$ of them had resilience values of below 10 points on a $0-100$ point scale, which was interpreted to be low urban resilience [19]. Also, a study in Ethiopia, using a climate resilience index (CRI) model concluded that the studied communities showed minimal resilience capacity [6]. Furthermore, the hybrid approach used to assess the resilience of Washington, DC and
Worcester, MA, showed that both cities resilience to climate change were mixed, with areas of both high and low resilience within each sector of the cities [4]. This shows that many cities in the world have low resilience and unprepared for both current and anticipated more severe future projected impacts of climate change.

$$
\text { HCRI }=\sum_{i=1}^{n} \frac{\mathrm{Ri}}{\mathrm{N}}=\frac{44.56}{19}=2.35 \text { points }
$$

\section{Conclusion}

The study has shown that households' resilience to climate change shocks and stresses in Yenagoa was unsatisfactory, as the calculated HCRI of 2.35 points on a 5 point scale was classified as low, based on the 19 indicators of households' 
resilience adopted for the study. In effect, most households' in Yenagoa are vulnerable to the impacts of climate change. In all, only seven indicators had a calculated resilience weight index of 2.50 points and above with the nineteenth indicator, access to good communication facilities having the highest calculated resilience weight index of 3.25 points; while 12 indicators had below 2.50 points, with the twelfth indicator, impact of government in the neighbourhood having the lowest value of 1.47 points. This is a clear indication that households' in Yenagoa are exposed to multiple areas of vulnerability to climate change shocks and stresses. The current level of households resilience means that in case of any major climate related disaster, most households will suffer great loss and the rate of recovery from the disaster may be slow.

\section{Recommendations}

In order to boost HRCC impacts in the metropolis, government should improve on the provision of infrastructural facilities in Yenagoa, since the impact of government was not felt in almost all the neighbourhoods in the metropolis. Also, government through its respective ministries, departments and agencies (MDAs) should design supportive livelihood improvement programmes for urban households through the establishment of micro finance bank, to improve households' access to investment funds, improve education and create job opportunities. In addition, the urban living environment should be enhanced with proper drainage channels, quality housing, adequate waste management and sanitation. Furthermore, robust information sharing platform and early warning system (using mobile phones) on climate change related issues should be developed in the metropolis. Government should also take seriously and act accordingly on the annual weather and flood predictions by the Nigerian Metrological Agency (NIMET) and Nigeria Hydrological ServicesAgency (NIHSA), respectively, since they are made to guide the government and the general public to take measures and develop strategies to mitigate andameliorate the expected negative impacts of climate-related and other shocks and stresses, which households are subjected to when they occur. These measures are capable of enhancing the resilience of households in Yenagoa to climate change.

\section{References}

[1] Rosenzweig C, Solecki W, Romero-Lankao P, Mehrotra S, Dhakal S, Bowman T and Ibrahim, S. A (2015) ARC3.2 Summary for City Leaders, Urban Climate Change Research Network, Columbia University. New York.

[2] Kim D and Lim U (2016) Urban Resilience in Climate Change Adaptation: A ConceptualFramework, Sustainability 8, 405; doi: 10.3390/su8040405.

[3] IPCC (2014) Climate Change 2014: Impacts, Adaptation, and Vulnerability. Part. A: Global and Sectoral Aspects; Cambridge University Press: Cambridge, UK.

[4] EPA (2017) Evaluating Urban Resilience to Climate Change:
A Multi-sector Approach, Office of Research and Development Washington, D. C, EPA/600/R-16/365F, Available online: www.epa.gov/research (Accessed 5 January 2018).

[5] Leichenko, R (2011) Climate change and urban resilience, Current Opinion in Environmental Sustainability, 3: 164168.

[6] Asmamaw, M, Mereta, S. T, Ambelu, A (2019) Exploring households' resilience to climate change-induced shocks using Climate Resilience Index in Dinki watershed, central highlands of Ethiopia. PLoS ONE 14 (7): e0219393. https://doi. org/10.1371/journal.pone.0219393

[7] Jones, L, Samman, E and Vinck, P (2018) Subjective measures of household resilience to climate variability and change: insights from a nationally representative survey of Tanzania. Ecology and Society 23 (1): 9. https://doi.org/10.5751/ES09840-230109

[8] Ohwo, O (2014) Housing Quality in Yenagoa, Bayelsa State, Nigeria, Nigerian Geographical Journal, New Series, Vol. 10 (1): 53-67.

[9] Koinyan, A. A., Nwankwoala, H. O. and Eludoyin, O. S. (2013) Water resources utilization in Yenagoa, Central Niger Delta: Environmental and health implications, International Journal of Water Resources and Environmental Engineering Vol. 5 (4): 177-186.

[10] Ohwo, O (2016) Residents' perception of urban aesthetics of Yenagoa, Bayelsa State, Nigerian, Nigerian Geographical Journal, New Series, Vol. 11 No. 1: 93-104.

[11] Krejcie, R. V and Morgan, D. W (1970) Determining Sample Size for Research Activities, Educational and Psychological Measurement, 30: 607-610.

[12] Ohwo, O (2019) Analysis of Households Vulnerability to Waterborne Diseases in Yenagoa, Nigeria, Journal of Water, Sanitation and Hygiene for Development, 9 (1): 71-79.

[13] Wong, P. P, Losada, I. J, Gattuso, J.-P, Hinkel, J, Khattabi, A, McInnes, K. L, Saito, Y and Sallenger, A. (2014): Coastal Systems and Low-Lying Areas. In: Climate Change 2014: Impacts, Adaptation, and Vulnerability. PartA: Global and Sectoral Aspects. Contribution of Working Group II to the Fifth Assessment Report of theIntergovernmental Panel on Climate Change [Field, C. B., Barros, V. R, Dokken, D. J, Mach, K. J, Mastrandrea, M. D, Bilir, T. E, Chatterjee, M, Ebi, K. L, Estrada, Y. O, Genova, R. C, Girma, B, Kissel, E. S, Levy, A. N, MacCracken, S, Mastrandrea, P. R and White, L. L (eds.)]. Cambridge University Press, Cambridge, United Kingdom and New York, NY, USA: 361-409.

[14] Flower, B., and M. Fortnam (2015) Urbanising disaster risk: vulnerability of the urban poor in Cambodia to flooding and other hazards. People in Need, Phnom Penh, Cambodia, https://www.preventionweb.net/files/47109_47109urbanisingd isasterriskreportin.pdf [Accessed, February 2, 2020].

[15] Iyorakpo, J (2015) Impact of rapid urbanization on environmental quality in Yenagoa Metropolis, Bayelsa State, Nigeria, European Scientific Journal, Vol. 11, No. 23; 255268.

[16] Rangwala, S. C (2011) Town Planning: A Text Book for Engineering Students $24^{\text {th }}$ Edition, Charotar Publishing House, PVT, Ltd, India. 
[17] Wan Mohd Rani W. N. M., Kamarudin K. H, Razak K. A, Hasan Che R and Mohamad Z (2018) Measuring Urban Resilience Using Climate Disaster Resilience Index (CDRI), International Conference on Geomatics and Geospatial Technology (GGT 2018), 3-5 September 2018, Kuala Lumpur, Malaysia.

[18] Tesso G, Emana B, Ketema M. (2012) Analysis of vulnerability and resilience to climate change induced shocks in North Shewa, Ethiopia, Agricultural Sciences, Vol. 3, No 6: 871-888.

[19] Suárez, M, Gómez-Baggethun, E, Benayas J and Tilbury D (2016) Towards an urban resilience index: A case study in 50 Spanish cities, Sustainability, 8, 774: 1-19. 